\title{
Penerapan Green Computing Pada Fakultas Sains dan Teknologi UIN Sunan Ampel Surabaya
}

\author{
Trisha Aida Syahputri ${ }^{1}$, Yusuf Amrozi ${ }^{2}$ \\ Prodi Sistem Informasi, Fakultas Sains dan Teknologi, UIN Sunan Ampel Surabaya \\ Jl. Ahmad Yani No. 117 Surabaya \\ Email: trishaidas@gmail.com
}

\begin{abstract}
ABSTRAK
Semakin berkembangnya teknologi, maka akan memberikan dampak pada lingkungan sumber daya alam. Apabila tidak membatasi penggunaan dari teknologi tersebut, akan memberikan dampak yang cukup besar bagi sumber daya alam. Green Computing merupakan langkah yang tepat untuk mengurangi emisi CO2 secara efektif. Fakultas Sains dan Teknologi pada UINSA merupakan fakultas yang memiliki komputer cukup banyak sedang mencoba untuk menerapkan teknologi Green Computing pada laboratoriumnya. Makalah ini membahas tentang beberapa hal yang perlu dilakukan sekaligus manfaat dan cara penerapan Green Computing dalam dunia pendidikan juga akan membahas tentang hal yang dilakukan oleh Fakultas SAINTEK UINSA untuk menerapkan teknologi Green Computing.
\end{abstract}

Kata Kunci: Green Computing, Green ICT, Global Warming

\begin{abstract}
As technology develops, it will have an impact on the natural resource environment. If it does not limit the use of these technologies, it will have a considerable impact on natural resources. Green Computing is the right step to reduce $\mathrm{CO} 2$ emissions effectively. The Faculty of Science and Technology at UINSA is a faculty that has quite a lot of computers trying to implement Green Computing technology in its laboratories and class. This paper discusses some of the things that need to be done and also the benefits and ways of implementing Green Computing in the world of education will also discuss about what was done by the UINSA SAINTEK Faculty to implement Green Computing technology.
\end{abstract}

Keywords: Green Computing, Green ICT, Global Warming

\section{Pendahuluan}

Teknologi berkembang semakin cepat dan maju, hal ini sudah ditandai dengan perkembangan teknologi yang berganti semakin cepat dan munculnya banyak inovasi-inovasi baru dari tiap-tiap produk agar dapat semakin memanjakan manusia yang menggunakannya. Hal ini juga dikarenakan teknologi adalah kebutuhan utama bagi sebagian besar manusia khususnya di Indonesia. Kebanyakan orang di Indonesia bahkan di dunia ini sudah mulai tergantung dengan teknologi yang semakin canggih dan semakin baru dan baru lagi.

Di era yang sangat maju ini, hampir seluruh orang membutuhkan komputer dan ponsel. Masyarakat sudah hampir tergantung dengan kedua alat teknologi tersebut, dan hal tersebut akan membuat penggunaan energi listrik menjadi berlebih dan akan berdampak pada produksi karbondioksida yang meningkat sehingga bumi akan terpengaruh dengan naiknya suhu bumi.

Menurut Badan Pusat Statistik, Indeks Pembangunan Teknologi Informasi dan Komunikasi (IPTIK) di Indonesia pada tahun 2016 adalah sebesar 4,34 pada skala $0-10$, yang dibagi menjadi 3 subindeks penyusun IP-TIK, yaitu subindeks akses dan infrasutruktur, penggunaan, dan keahlian. Juga menurut statista.com, total penggunaan handphone dilihat dari nomor pengguna di dunia di tahun 2019 adalah sejumlah 4,68 miliar, ini berbanding cukup jauh jika dibandingkan dengan 4 tahun sebelumnya yaitu tahun 2015 dengan pengguna ponsel diperkirakan mencapai 4,15 miliar. Mungkin jumlah yang tertera masih berbanding sedikit dibandingkan dengan jumlah manusia yang ada di dunia ini, tapi tak lupa, teknologi berkembang sangat cepat, bukan tidak mungkin dalam beberapa tahun ke depan teknologi dapat menjadi sumber terbesar emisi $\mathrm{CO} 2$ karena semakin banyaknya pengguna teknologi informasi. Terlebih diketahui bahwa menurut Gartner (2007) dalam Jayadih dkk (2016), mengatakan bahwa semua penghasil emisi $\mathrm{CO} 2$ di dunia sekitar 2 persen diketahui berasal dari industri TIK[1].

Untuk itu dibutuhkan sebuah gerakan yang dapat memperhatikan agar industri dapat menghasilkan produkproduk yang ramah lingkungan, Green Computing adalah langkah yang tepat[2]. Green Computing atau dalam Bahasa Indonesia disebut dengan komputasi hijau merupakan seluruh proses yang terkait dengan teknologi komputasi dan informatisasi, mulai dari pengkajian, perencanaan, pembuatan, penggunaan sampai dengan pemusnahan sumber daya komputer dan peralatan komputasi terkait, secara efektif dan efisien dengan mengutamakkan prinsip terjaganya ramah lingkungan. Menteri Energi dan Sumber Daya Mineral Republik 
Indonesia juga telah turut berpartisipasi dalam gerakan ini dengan keluarnya Peraturan Menteri Energi dan Sumber Daya Mineral Republik Indonesia Nomor : 13 Tahun 2012 Tentang Penghematan Pemakaian Tenaga Listrik.

Tujuan dari penelitian ini adalah untuk mengedukasi dalam penerapan Green Computing dalam praktik sehari-hari. Jika gerakan ini diimplementasikan, pelaksanaan Green Computing pada suatu instansi atau perusahaan itu akan memberikan dampak positif yaitu selain dapat mengurangi emisi $\mathrm{CO} 2$ yang dihasilkan, juga dapat menekan biaya sumber daya yang dikeluarkan[3].

\section{Metode Penelitian}

Penelitian ini merupakan penelitian kualitatif yang menggunakan metode penelitian studi literatur yaitu dengan cara mempelajari teori-teori tentang Green Computing dari jurnal-jurnal nasional dan internasional, website, undang-undang, artikel, dan buku serta literaturliteratur lainnya yang memiliki hubungan dengan penelitian ini. Selain menggunakan metode studi literatur, penelitian ini juga menggunakan observasi langsung yaitu dengan pencarian data dengan datang di tempat langsung yang didapat memiliki hubungan dengan penelitian ini.

\section{Penerapan Green Computing}

Deepanjan Sen dan Dilip Roy Chowdhury (2016) menjabarkan dalam penelitiannya tentang pemilihan penggunaan peralatan computer seperti di bawah ini[3]:

1. Desktop vs. Laptop

Dari hasil penelitiannya, memberi hasil bahwa apabila membandingkan antara penggunaan komputer dekstop dengan laptop, laptop akan mengkonsumsi daya komputer lebih rendah daripada dekstop per-bulan dan per-tahunnya dalam keadaan monitor bekerja. Dan ternyata setelah pula dilakukan penelitian lebih lanjut, diketahui bahwa setelah dekstop dan laptop dijadikan mode tidur ketika tidak digunakan, ternyata menggunakan daya yang jauh lebih rendah dibandingkan penuh dengan mode kerja. Perbandingan tersebut akan digambarkan dengan diagram di bawah ini:

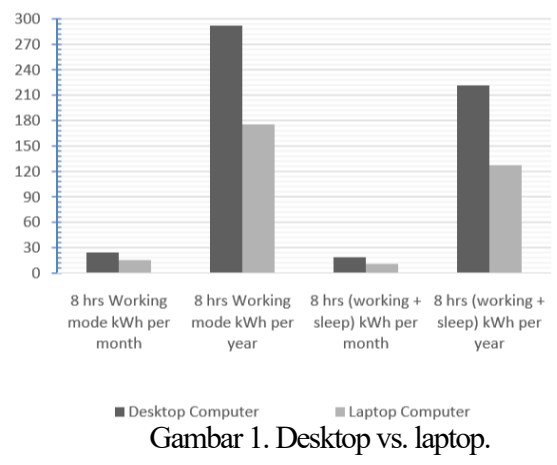

Disini memberikan arti bahwa penggunaan laptop lebih disarankan daripada penggunaan desktop, dan pula lebih disarankan menggunakan mode tidur ketika computer sedang tidak digunakan.
2. CRT vs. LCD vs. LED

Dari hasil penelitian tersebut, jika dilihat dari konsumsi daya rata-rata antara monitor CRT, LCD, dan LED setiap bulannya, konsumsi daya bulannya relatif lebih tinggi CRT dibanding LCD dibanding LED (CRT $>$ LCD $>$ LED). Jadi disini disarankan untuk menggunakan LED dibandingkan LCD apalagi CRT.

K. Shalini dan K. Naga Prasanthi (2013) mendeskripsikan terdapat 4 prinsip utama dari Green IT yang difokuskan pada berbagai bidang dan kegiatan[4].

1. Green use: Mengurangi konsumsi energi server, komputer dan sistem informasi lainnya dan menggunakannya dengan ramah lingkungan, misalnya virtualisasi, mematikan komputer ketika tidak digunakan, dan lainnya.

2. Green design: Mendesain komponen yang efisien energi dan berwawasan lingkungan, komputer, server dan peralatan dan lebih mementingkan masa depan komponen elektronik misalnya desain ramah lingkungan, menggunakan monitor LED, dan lainnya.

3. Green manufacturing: Setiap proses dalam pembuatan komponen elektronik, komputer, dan subsistem rekanan lainnya harus menyiratkan dampak rendah atau tidak sama sekali terhadap lingkungan.

4. Green disposal: Merencanakan perbaikan dan penggunaan kembali komputer lama. Juga dengan melakukan proses daur ulang untuk komputer yang tidak lagi digunakan atau komponen elektronik lainnya harus disiapkan.

\section{Manfaat Green Computing}

Disini dapat dijabarkan beberapa manfaat dari green computing[5], yaitu:

1. Dapat menghemat daya juga menghemat listrik.

2. Mengurangi emisi CO2.

3. Terhindar dari krisis listrik berlanjut

4. Ramah lingkungan.

5. Mengurangi penggunaan kertas.

6. Memperpanjang usia komputer.

\section{Hasil dan Pembahasan}

Pada dasarnya Fakultas Sains dan Teknologi UIN Sunan Ampel Surabaya (Fakultas SAINTEK UINSA) sudah menerapkan beberapa langkah untuk menghemat energi dan menerapkan beberapa implementasi green computing. Meskipun belum terlalu familiar, tetapi beberapa langkah sudah dilakukan. Dengan tidak kenalnya dengan green computing, dan tidak mengetahui akibat yang didapatkan apabila kita tidak melakukan hemat energi, hal tersebut dapat membuat masyarakat menggunakan energi tanpa aturan dan sekenanya saja.

Sebagai contoh yang paling sering dialami adalah dengan membiarkan komputer tetap menyala 
meskipun tidak digunakan, selain itu hal yang juga tak kalah sering dialami adalah ketika setelah mengisi baterai pada laptop laptop dan baterai sudah penuh alih-alih mencabut steker dari soket, justru banyak masyarakat yang masih mencabut kabel dari laptopnya saja, padahal kegiatan tersebut masih mengambil daya dari listrik.

Fakultas Saintek memiliki sebuah laboratorium yang digunakan untuk seluruh prodi di fakultas tersebut, yang bernama laboratorium integrasi. Disana terdapat laboratorium komputer, laboratorium bahasa, laboratorium untuk jurusan biologi, dan lain-lain. Pada laboratorium komputer terdapat satu buah LCD Projector ditambah Bracket dan Screennya, 25 set komputer dan 1 server, 1 printer, $2 \mathrm{AC}$ dan beberapa lampu. Apabila seluruh laboratorium bekerja, dan apabila seluruh peralatan yang ada di dalamnya beroperasi itu akan membutuhkan sangat banyak sumber daya yang digunakan. Untuk itu sangat perlu diadakannya hemat energi dan penerapan green computing[6].

Sebenarnya hal utama yang harus ditanamkan adalah sebuah kesadaran dari masing-masing pengguna, tetapi Fakultas SAINTEK telah berusaha memberikan upaya-upaya agar dapat menghemat energi. Dibawah ini akan dijelaskan beberapa hal yang telah dilakukan oleh Fakultas SAINTEK untuk menghemat energi dan menerapkan green computing, antara lain:

1. Pemasangan Tulisan Untuk Hemat Energi.

Seperti yang telah dikatakan sebelumnyam bahwa hal utama yang harus dilakukan adalah dengan menanamkan kesadaran dari masing-masing pengguna untuk melakukan hemat energi dan green computing, disini Fakultas SAINTEK membuat sebuah langkah yaitu dengan membuat tulisan dalam bingkai yang memberi himbauan untuk menghemat energi dengan kata kiasan seperti yang ada pada Gambar 2 .

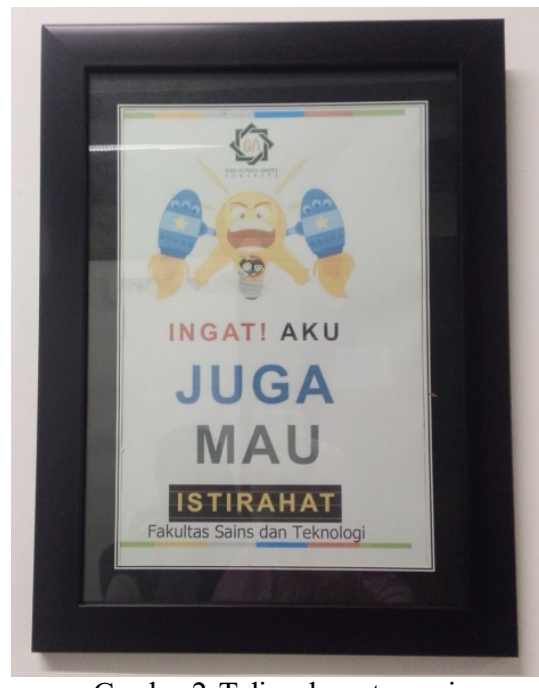

Gambar 2. Tulisan hemat energi

Disana bertuliskan bahwa "INGAT! AKU JUGA MAU ISTIRAHAT" dengan animasi lampu yang sedang kelelahan karena selalu digunakan. Ini menggambarkan bahwa jangan terus menerus menggunakan listrik untuk menghemat energi.

2. Mematikan Peralatan Elektronik Apabila Tidak Digunakan.

Laboratorium Integrasi menghentikan operasinya jika jam sudah menunjukkan pukul 16.00 sore, itu artinya seluruh alat elektronik yang ada pada laboratorium tersebut harus sudah dalam keadaan mati karena sedang tidak lagi digunakan, setiap mahasiswa diharuskan memastikan agar seluruh komputer ataupun peralatan lain haruslah mati sebelum meninggalkan ruangan laboratorium.

Selain itu apabila mahasiswa memilih untuk menggunakan laptopnya dibandingkan dengan komputer yang telah disediakan laboratorium, mahasiswa akan mematikan komputer yang ada di hadapannya apabila tidak lagi digunakan.

3. Dosen Kebanyakan Memilih Menggunakan Laptop Dibanding Desktop.

Seperti yang sudah dijelaskan sebelum bab pembahasan, disana terdapat penelitian yang mengatakan bahwa penggunaan komputer desktop membutuhkan daya yang lebih besar dibandingkan laptop, dengan ini beberapa dosen memilih untuk menggunakan laptop pribadi, selain karena data-data sudah banyak yang tersimpan di laptop.

4. Menggunakan Kembali (Reuse) Komputer Yang Tidak Lagi Digunakan.

Dengan berkembang pesatnya teknologi, membuat Fakultas SAINTEK ingin maju dengan menggunakan teknologi yang terbaru. Dengan keinginan untuk maju ini, Fakultas SAINTEK tak segan untuk mengganti teknologi lama dan membeli teknologi yang terbaru. Lalu apakah komputer lama itu akan dibuang begitu saja? Tidak. Beberapa komputer masih digunakan untuk praktik-praktik seperti pada mata kuliah Jaringan untuk prodi Sistem Informasi, dan lain-lain. Komputer juga bisa digunakan untuk hal lain yang tidak membutuhkan teknologi terbaru dalam penggunaan sehari-harinya.

5. Penggunaan Komputer LED

Pada bagian metode penelitian, dijelaskan bahwa urutan dari penggunaan daya terbesar adalah CRT kemudian LCD dan kemudian LED. Fakultas Sains dan Teknologi telah menggunakan komputer LED pada Laboratorium Komputernya.

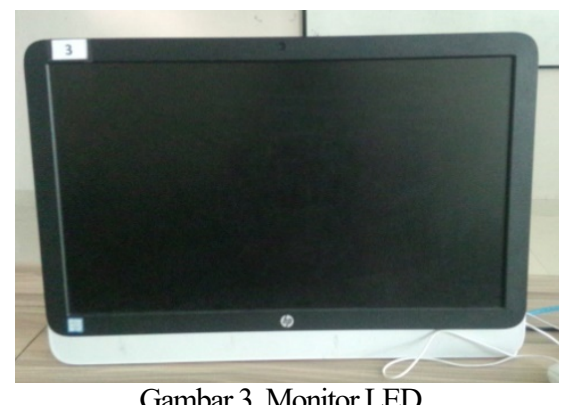

Dengan menggunakan monitor LED, dapat mengurangi konsumsi listrik yang lebih hemat dari 
monitor CRT bahkan dari monitor LCD juga. Selain itu, dengan menggunakan monitor LED juga dapat menikmati keunggulan seperti kontras gambar yang sangat tajam hingga jutaan pixels. Tak hanya itu, dengan menggunakan monitor LED, juga dapat menambah usia pemakaian menjadi lebih panjang, tentu ini merupakan termasuk green computing, karena selain hemat energi, menggunakan monitor LED juga dapat memperpanjang usia sehingga tidak mudah rusak dan harus mengganti yang baru.

6. Penggunaan Sistem Informasi Akademik (SIAKAD).

Dalam hal mengurangi penggunaan kertas, Fakultas SAINTEK, lebih tepatnya UIN Sunan Ampel Surabaya menggunakan Sistem Informasi Akademik. Disini dapat melakukan hal-hal yang seharusnya dilakukan secara manual dengan kertas, tetapi bisa divirtualkan dengan Sistem Informasi tersebut.

Selain dalam hal mengurangi penggunaan kertas, SIAKAD juga dapat menjadi kelas pengganti, dibandingkan bertemu langsung yang akan menghabiskan banyak penggunaan listrik, sehingga kelas diganti menjadi kelas online yaitu melalui SIAKAD, semisal pemberian tugas, materi, maupun diskusi, dapat dilakukan di SIAKAD ini.

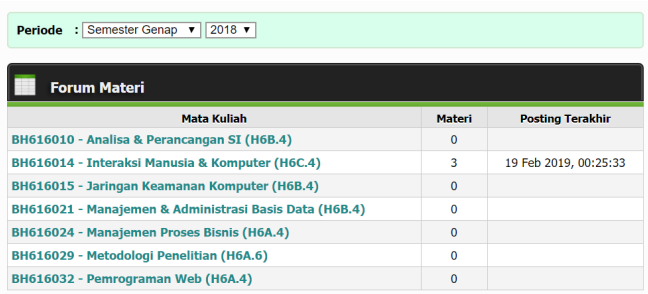

Gambar 4. Forum Materi SIAKAD.

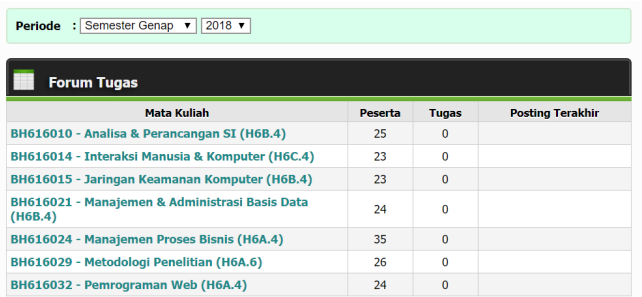

Gambar 5. Forum Tugas SIAKAD.

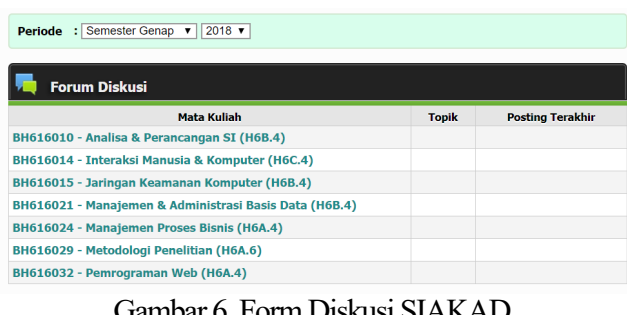

Gambar 6. Form Diskusi SIAKAD.

Dengan adanya SIAKAD, mahasiswa dan dosen tidak perlu bertemu langsung, sehingga tidak menggunakan daya listrik yang banyak, pula dengan adanya Sistem Informasi Akademik, akan mengurangi jumlah penggunaan kertas.
7. Penggunaan E-Education

Tidak hanya melalui SIAKAD, tetapi mahasiswa dan dosen juga sering kali melakukan diskusi dan pengiriman tugas melalui E-Education seperti Google Classroom, disana biasanya dosen memberikan tugas maupun materi kepada mahasiswa. Dengan google classroom, mahasiswa juga bisa berdiskusi atau bertanya pada dosen secara personal maupun umum agar bisa diketahui oleh teman-teman yang lain, mahasiswa juga bisa bertanya disana dan berdiskusi bersama temanteman lainnya. Fungsinya tak jauh beda dari SIAKAD, hal yang dapat diambil adalah dengan menggunakan Google Classroom, mahasiswa dan dosen tidak perlu datang ke kelas dan menggunakan daya listrik, tanpa hal tersebut kelas tetap bisa berjalan[7].

Selain penggunaan Google Classroom, mahasiswa dan dosen seringkali juga berdiskusi melalui sosial media seperti WhatsApp, disana mahasiswa menanyakan pada sebuah group kelas apabila mendapatkan kesulitan, dan disana dosen dapat menjawab, dan apabila dosen masih belum sempat untuk menjawab, teman-teman yang lain yang mungkin tahu dapat juga menjawab. Dalam hal ini mahasiswa dan dosen juga tidak perlu datang dan menggunakan daya listrik yang banyak.

\section{Kesimpulan}

Fakultas Sains dan Teknologi UIN Sunan Ampel Surabaya telah melakukan beberapa upaya untuk menerapkan green computing. Diharapkan Fakultas Sains dan Teknologi UIN Sunan Ampel Surabaya turut dapat membantu dalam mengurangi emisi $\mathrm{CO} 2$ dan mengurangi global warming dengan melakukan beberapa upaya tersebut. Tetapi, pada dasarnya hal utama yang harus diupayakan adalah kesadaran diri sendiri, seperti pada AlQur'an surat ar-Rad:11, "Sesungguhnya Allah tidak akan mengubah keadaan suatu kaum hingga mereka merubah keadaan yang ada pada diri mereka sendiri.”.

\section{Daftar Pustaka}

[1] Budhi, R.K. (2011). Penerapan Green Computing Di Fakultas Teknologi Informasi Dan Komunikasi Universitas Semarang, Jurnal Transformatika, 8(2), 352-365.

[2] Nugroho, B.A. (2013). Penerapan Komputasi Hijau di Lingkungan Pemerintah Daerah Dan Perusahaan Bidang Teknologi Informasi, Jurnal Penelitian Komunikasi, 16(1), 91-100.

[3] Sen, D., and Chowdhury, D. R., Green Computing : Efficient Practices And Applications. (2016). International Journal of Computer Sciences and Engineering, 4(1), 3847. 
[4] Shalini, K., and Prasanthi, K. N., Green Computing. (2013). Journal of Telematics and Informatics, 1(1), 1-13.

[5] Warijono. (2016). Penerapan Green Computing Dalam Upaya Efesiensi Sumber Daya Di Amik BSI Tegal, Indonesian Journal on Software Engineering, 2(1), pp. 52-56.

[6] Rusdan, M. (2019). PERENCANAAN PENERAPAN GREEN COMPUTING DI LABORATORIUM KOMPUTER UMUM (LKU) UNIVERSITAS WIDYATAMA BANDUNG. Jurnal TEDC, 11(3), 262-267.
[7] HAMZAH, M. L., RUKUN, K., RIZAL, F., \& PURWATI, A. A. (2019). A review of increasing teaching and learning database subjects in computer science. Revista ESPACIOS, 40(26). 